\title{
Real Time Monitoring of Extreme Rainfall Events with Simple X-Band Mini Weather Radar
}

\author{
Silvano Bertoldo, Claudio Lucianaz, Marco Allegretti, Giovanni Perona \\ CINFAI (National Consortium for the Physics of Atmosphere and Hydrosphere), localunit c/o DET (Department \\ of Electronics and Telecommunications), Politecnico di Torino, Turin, Italy \\ Email: silvano.bertoldo@polito.it
}

Received 12 February 2016; accepted 18 April 2016; published 21 April 2016

Copyright (C) 2016 by authors and Scientific Research Publishing Inc.

This work is licensed under the Creative Commons Attribution International License (CC BY). http://creativecommons.org/licenses/by/4.0/

\section{(c) (i) Open Access}

\section{Abstract}

Real time rainfall events monitoring is very important for a large number of reasons: Civil Protection, hydrogeological risk management, hydroelectric power purposes, road and traffic regulation, and tourism. Efficient monitoring operations need continuous, high-resolution and large-coverage data. To monitor and observe extreme rainfall events, often much localized over small basins of interest, and that could frequently causing flash floods, an unrealistic extremely dense rain gauge network should be needed. On the other hand, common large C-band or S-band long range radars do not provide the necessary spatial and temporal resolution. Simple short-range X-band mini weather radar can be a valid compromise solution. The present work shows how a single polarization, non-Doppler and non-coherent, simple and low cost $X$-band radar allowed monitoring three very intense rainfall events occurred near Turin during July 2014. The events, which caused damages and floods, are detected and monitored in real time with a sample rate of 1 minute and a radial spatial resolution of $60 \mathrm{~m}$, thus allowing to describe the intensity of the precipitation on each small portion of territory. This information could be very useful if used by authorities in charge of Civil Protection in order to avoid inconvenience to people and to monitor dangerous situations.

\section{Keywords}

X-Band Radar, Extreme Rainfall Event, Precipitation Monitoring, High Temporal Resolution, High Spatial Resolution, Real Time Monitoring, Single Polarization 


\section{Introduction}

Accurate observation and real time monitoring of precipitations in terms of intensity and location are important for different applications, starting from hydro-geological risk management to hydroelectric power management, from road maintenance to emergency planning, from tourism to real time traffic management.

The most traditional method of real time rainfall monitoring using rain gauges connected in a network is not expensive but only provides punctual measurements on the ground. Other specific instruments such as disdrometers and microwave links can be used, even if they cannot capture the spatial variability of rainfall over large areas such as river catchments [1]. They cannot be used by simple technicians and operators of institution responsible for environmental monitoring and natural hazard prevention, like for instance, Civil Protection volunteers, who often do not have the required skills to use them.

Most common C-band and S-band long range radar systems can offer an immediate way for measuring precipitation over a certain area. They often do not provide sufficient time and space resolutions, especially if they are used over complex orographic regions where their beam is often partially shielded by relieves, and where their performance needs post processing algorithms [2] [3], thus implying they are not adequate for real time monitoring of intense and localized rainfall events.

Simple X-band mini weather radar systems are a solution to monitor and observe in real time rain events with a good resolution in space and time at, last but not least, low costs. They can be used standalone as well as integrated in already existing networks devoted to rainfall monitoring. In the following, after a very short description of an X-band weather radar system, it will be shown how it is very useful for extreme rainfall event real time monitoring examining three events occurred during July 2014 near Turin. The radar was installed on the roof of the Department of Electronic and Telecommunications of Polytechnic of Turin (Italy).

\section{Radar Meteorology}

Before entering into details about the presentation of the results related to real time monitored of extreme rainfall events, it is important to briefly point out the basic concepts of radar meteorology theory [4].

The backscattered power caused by rain drops is, unfortunately, only indirectly linked to the rain rate $R$ measured in $\mathrm{mm} / \mathrm{h}$. The backscattered power caused by the hydrometeors and detected by the radar is, in fact, directly proportional to the radar reflectivity factor $Z$. A fundamental quantity for precise assessment of both $Z$ and $R$ is the Drop Size Distribution (DSD), $N(D)$, which is defined as the number of rain drops per unit volume in the diameter interval $\delta D$, i.e. between the diameter $D$ and $D+\delta D$. The radar reflectivity factor, $Z$, is defined as the $6^{\text {th }}$ moment of the DSD, namely:

$$
Z=\int_{0}^{\infty} N(D) D^{6} \mathrm{~d} D
$$

In radar meteorology, it is common to use the dimensions of millimeters for drop diameter $D$ and to consider the summation (integral) to take place over a unit volume of $1 \mathrm{~m}^{3}$. Therefore, the conventional unit of $Z$ is in $\mathrm{mm}^{6} / \mathrm{m}^{3}$. For the assessment of rain rate, another fundamental quantity is needed: the terminal drops fall velocity as a function of the diameter, $v(D)$. Since it is common to use $\mathrm{m} / \mathrm{s}$ as measure unit, then the relationship (2) is:

$$
R=6 \cdot 10^{-4} \cdot \pi \int_{0}^{\infty} N(D) D^{3} v(D) \mathrm{d} D
$$

If precipitating hydrometeors in the radar backscattering volume were all spherical raindrops (which is almost never the real case) and the DSD could be described to a good approximation by an exponential DSD, then a simple power-law would relate $Z$ to $R$. The radar reflectivity $Z$ is related to the rainfall amount $R$ with the law reported in Equation (3), where $a$ and $b$ are numerical coefficient chosen on the basis of empirical experiments and analytic studies.

$$
Z=a R^{b}
$$

\section{The X-Band Mini Weather Radar}

In recent years a lot of other X-band meteorological radar networks appeared, including simple single polariza- 
tion radar systems and more complex polarimetric, coherent and Doppler weather radars. Since 2010 also the Remote Sensing Group (RSG, www.remotesensinggroup.polito.it) of Department of Electronic and Telecommunications of Polytechnic of Turin, local unit of CINFAI (Consorzio Interuniversitario Nazionale per la Fisicadelle Atmosfere e delleIdrosfere) developed an X-band mini radar system exclusively devoted to monitor rain [5], in cooperation with Envisens Technologies s.r.l. (www.envisens.com).

The X-band mini weather radar is very simple (Figure 1). It is an un-coherentpulsednon Doppler radar, exploiting only the vertical polarization. It usually transmits $400 \mathrm{~ns}$ pulses with a standard pulse repetition frequency (PRF) equals to $800 \mathrm{~Hz}$. It is characterized by a peak power of $10 \mathrm{~kW}$ and its maximum useful range was set to $30 \mathrm{~km}$. It has a fixed elevation parabolic antenna with $34 \mathrm{~dB}$ gain and 3.6 Half Power Beam Width (HPBW) usually installed with a tilt of about $2.5^{\circ}$ above the horizontal plane. The main characteristics are reported in Table 1 and Table 2.

This radar is exclusively devoted to rain measurements and monitoring and can be calibrated according to a Bulk Adjustment (BA) procedure as reported in [6] to improve its Quantitative Precipitation Estimation (QPE).

It is already demonstrated that such instruments are useful tools to monitor complex rain fields both in urban areas and complex orography environment, thanks to their high time resolution equals to 1 minute that allows to observe rain fields quick displacement in real time, while it shigh spatial resolution equals to 60 meters allows to monitor with sufficient details rain fields within a maximum range of $30 \mathrm{~km}$ [7].

The mini weather radar does not require any particular specific maintenance and it has the possibility to be remotely controlled with software updates, make such radar able to conveniently cover limited areas without dramatic impacts on the environment, and without the need of strong logistic support.

A specific procedure to control its stability and to assure correct rainfall measurement has been developed as well. It is based on the analysis of the Cumulative Distribution Function (CDF) of clutter echoes acquired in clear sky condition [8]-[10] with the clutter filter (which is usually active) turned off. By periodically running the software implementing the procedure it is possible to detect potential de-calibration of the radar and even equipment failures.

\subsection{Radar Products}

The X-band mini weather radar described above allows to obtain some different radar products, most of them useful for real time monitoring operation, which is the main object of the present work. Among the available radar products it is possible to identify the followings.
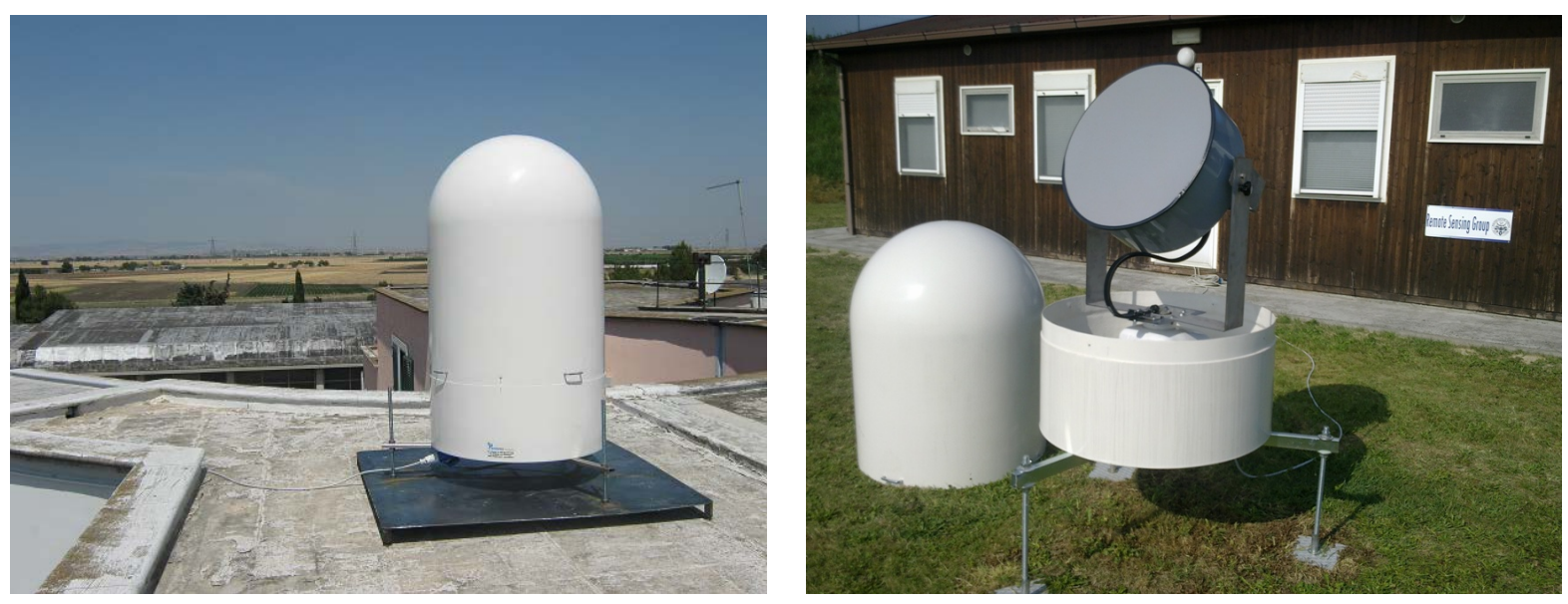

Figure 1. Short range X-band single polarization mini weather radar with high temporal and spatial resolution.

\begin{tabular}{l} 
Table 1. X-band mini weather radar sensitivity. \\
\begin{tabular}{cc}
\hline Radar Reflectivity (Z) & $20 \mathrm{dBZ}$ \\
& $0.5 \mathrm{~mm} / \mathrm{h}$ \\
Rainfall Rate (R) & According to Joss and Waldvogel ZR-equation (1990) [11]
\end{tabular} \\
\hline
\end{tabular}


Table 2. X-band mini weather radar technical characteristics.

\begin{tabular}{|c|c|}
\hline Radome & \\
\hline Height & $150 \mathrm{~cm}$ \\
\hline Diameter & $90 \mathrm{~cm}$ \\
\hline Material & Polyester \\
\hline \multicolumn{2}{|l|}{ Transmitter } \\
\hline Peak power & $10 \mathrm{~kW}$ \\
\hline Pulse length & 800 ns but configurable \\
\hline Transmitted frequency & $(9410 \pm 30) \mathrm{MHz}$ \\
\hline Pulse Repetition Frequency (PRF) & $800 \mathrm{~Hz}$ (but configurable \\
\hline Modulator & Solid state \\
\hline \multicolumn{2}{|l|}{ Receiver } \\
\hline Receiver type & Logarithmic, solid state \\
\hline Dynamic range & From 0 to $-100 \mathrm{dBm}$ \\
\hline Intermediate Frequency (IF) & $60 \mathrm{MHz}$ \\
\hline Receiver filter bandwidth & $(20 \pm 2) \mathrm{MHZ}$ \\
\hline \multicolumn{2}{|l|}{ Antenna } \\
\hline Gain & $34 \mathrm{~dB}$ \\
\hline HPBW & $3.6^{\circ}$ \\
\hline Polarization & Vertical \\
\hline Elevation & $2^{\circ}$ (but configurable) \\
\hline \multicolumn{2}{|l|}{ Other technical specifications } \\
\hline Front end & Microwave integrated circuit \\
\hline Noise figure & $<3.5 \mathrm{~dB}$ \\
\hline Doppler & NO \\
\hline Antenna rotation speed & $(22 \pm 2)$ r. p. m. \\
\hline Power & $220 \mathrm{Vdc}-<150 \mathrm{~W}$ \\
\hline
\end{tabular}

- Real time maps with temporal resolution of 1 minute and spatial resolution of processed maps of $60 \mathrm{~m}$ (Figure 2). These maps are available in different formats:

- Digital Numbers (DN, between 0 and 255).

- Radar reflectivity (Z) [dBZ].

○ Rainfall Rate (R) [mm/h].

- Cumulated rain maps over different time intervals (Figure 3). Common time interval are 1 hour, 6 hours, 12 hours, the previous day, the last 7 previous day, but the reference intervals are potentially configurable according to specific users' needs. They can be computed with a time interval down to 3 minutes.

- Meteoradar-IT Android(C App (Figure 4). Radar data can be browsed using the official Android(C application Meteoradar-IT freely downloadable from Google $\subset$ Store. 


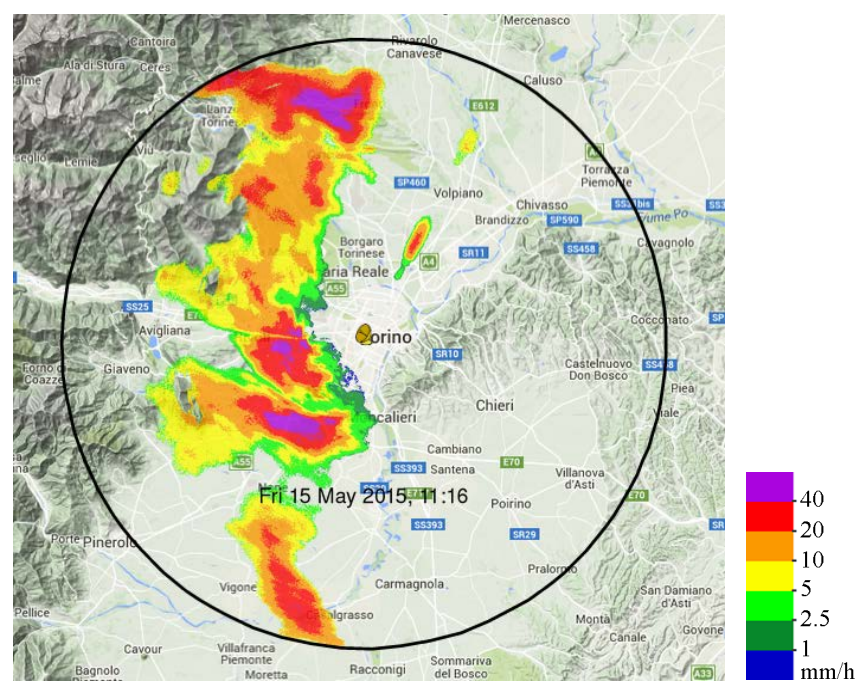

Figure 2. Example of real time map obtained with X-band mini weather.

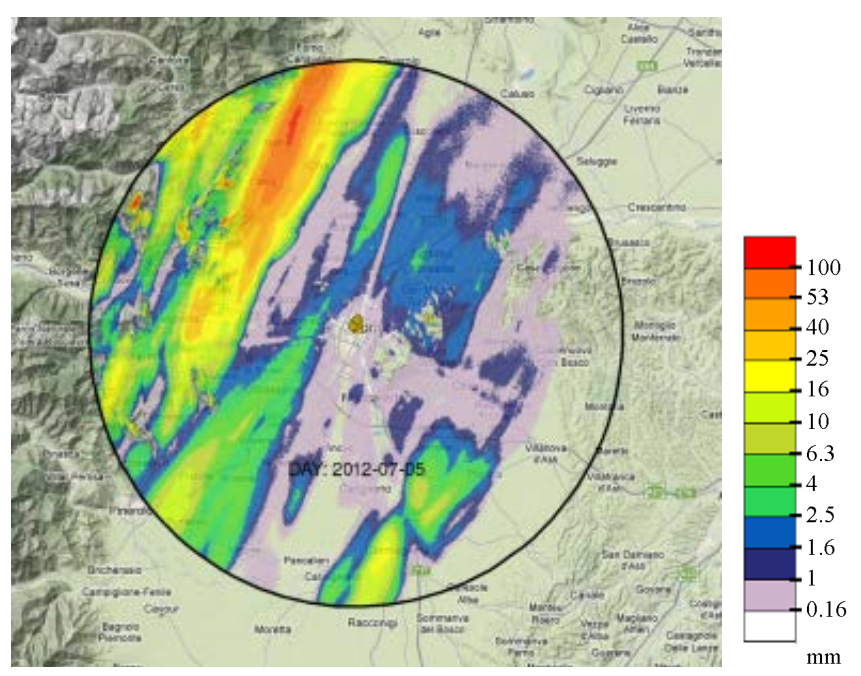

Figure 3. Example of cumulate rain map related to the 24 hour.

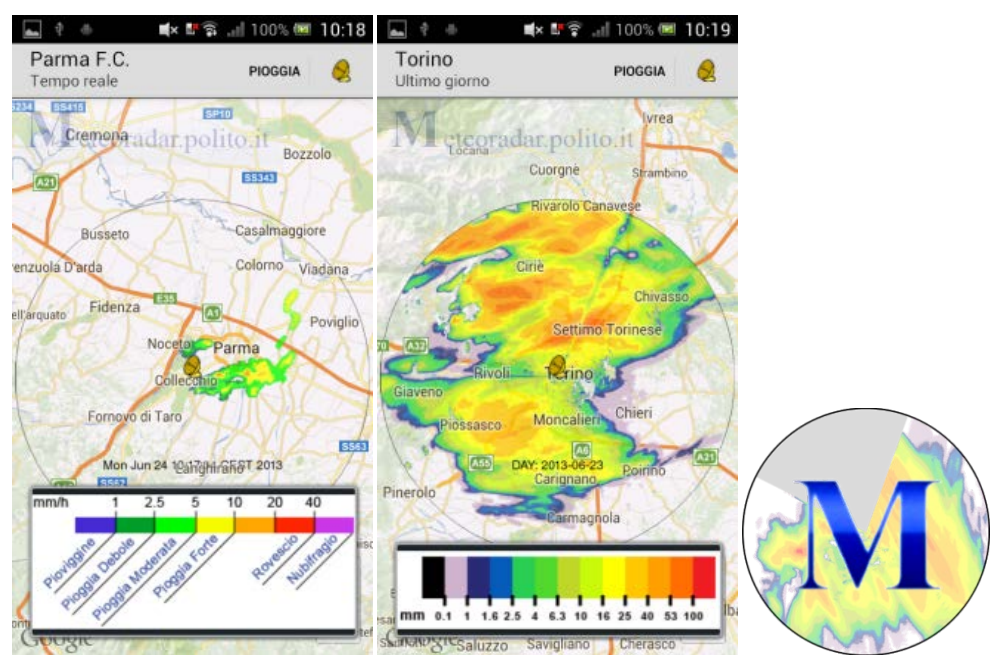

Figure 4. Screenshot of Meteoradar-IT Android App. 


\section{Brief Meteorological Analysis of Rainfall Events during July 2014}

Before analyzing the extreme rainfall events occurred during July 2014 and monitored in real time by the $\mathrm{X}$-band mini weather radar it is necessary to make some meteorological and climatological considerations about the examined month.

From a climatological point of view, and considering the amount of rain fallen over Piedmont, a region in the North-Western part of Italy, the month of July 2014 was an exceptional case in the last 60 years. The total monthly average amount of observed rainfall precipitation was higher than about two and a half times if compared with the reference standard period 1971-2000. In the same month, the temperatures were below the average values of the same reference period. Indeed, there were about 20 rainy almost consecutive days involving the whole Piedmont region with particular focus on the Northern areas of the river Po.

In particular, according to the ARPA Piemonte (Azienda Regionale per la Protezione Ambientaledel Piemonte) [12], July 2014 was the most rainy July since the year 1958 (i.e. since data are available in the ARPA archives). It presented an average precipitation amount of about $163 \mathrm{~mm}, 168 \%$ (corresponding to $103 \mathrm{~mm}$ ) than the normal. Considering the temperature July 2014 has been the $13^{\text {th }}$ coldest July in the time series of the last 57 years, with a negative anomaly of $-1.1^{\circ} \mathrm{C}$.

ECMWF (European Center for Medium-range Weather Forecasts) data processed by ARPA Piemonte [11] show the barometric anomaly situation responsible for the weather during the month of July 2014. Figure 5 shows the anomaly of the geopotential height of $500 \mathrm{hPa}$ compared to the average of the period 1971-2000. The bar on the right indicates the anomaly with respect to the standard values. There is a large area characterized by a negative anomaly of pressure on Southern Europe with minimum value on the French Riviera, while Northern Europe presents higher values if compared to the standard.

The represented anomaly allows the North Atlantic circulation to be particularly active and to create the proper conditions to generate a large number of very intense rainfall events over the Mediterranean area i in green in Figure 5.

A detailed analysis of all the rainfall events is reported in a complete report realized by ARPA Piemonte in 2014 [13]. In this work it is reported the analysis of real time monitoring of the 3 most extreme rainfall events occurred around Turin during the considered month, and in particular related to the following 3 days: $7^{\text {th }}$ July, $20^{\text {th }}$ July, $24^{\text {th }}$ July.

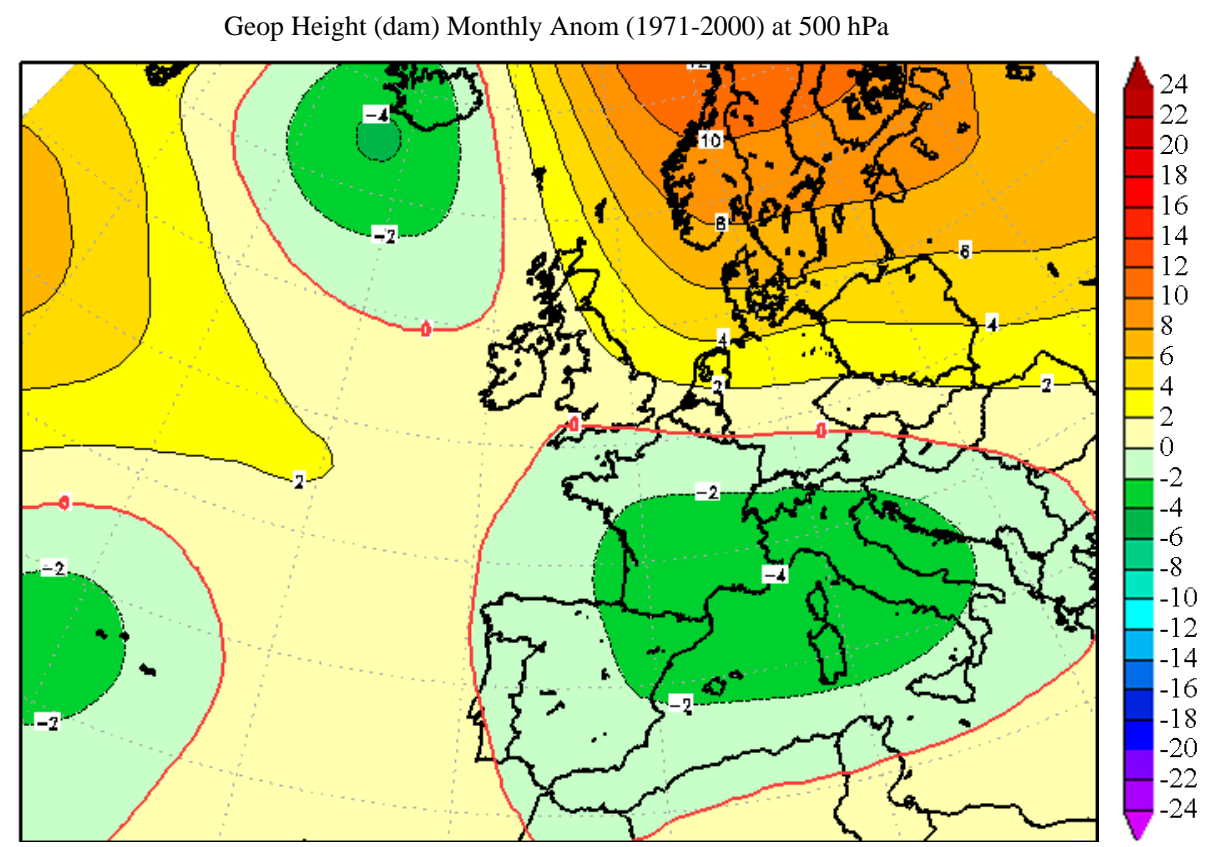

ECMWP-ECMWF_EURNA_1000-JUL 2014 Monthly Average

Figure 5. Anomaly of geopotential height at $500 \mathrm{hPa}$ for the month of July 2014 compared to the average of the standard reference period. Courtesy from ARPA Piemonte [11]. 


\section{Real Time Monitoring with X-Band Mini Weather Radar}

\section{1. $7^{\text {th }}$ July 2014}

Among the three days of extreme rainfall events considered in this work, $7^{\text {th }}$ July 2014 is certainly the day when the thunder storms caused more damages, since they were the most intense and persistent over small basins.

During the whole day a lot of different small thunderstorms occurred around Turin, over the area monitored by the X-band mini weather radar. Up to $50 \mathrm{~mm}$ of total fallen water was measured (Figure 6). Three extreme intense rainfall events caused intense flash floods over three different areas and were very well monitored in real time using the radar system.

1) Between 16.00 CEST and 16.40 CEST in the Northern part of the area monitored by the radar, more than $60 \mathrm{~mm}$ of rain fell in about half an hour. Some small villages were flooded (Figure 7) and different roads were closed. Lots of car drivers were forced to stay in their car because the water reached up half of the car doors. The radar measured a rainfall rate of more than $50 \mathrm{~mm} / \mathrm{h}$. The radar acquired a map every minute but here, for simplicity, only some significant maps are reported (Figure 8).

2) Between 17.00 CEST and 18.50 CEST a certain number of different very intense rainfall events stand on the same South-Western part of the monitored area causing a lot of damages. The traffic was literally stuck for

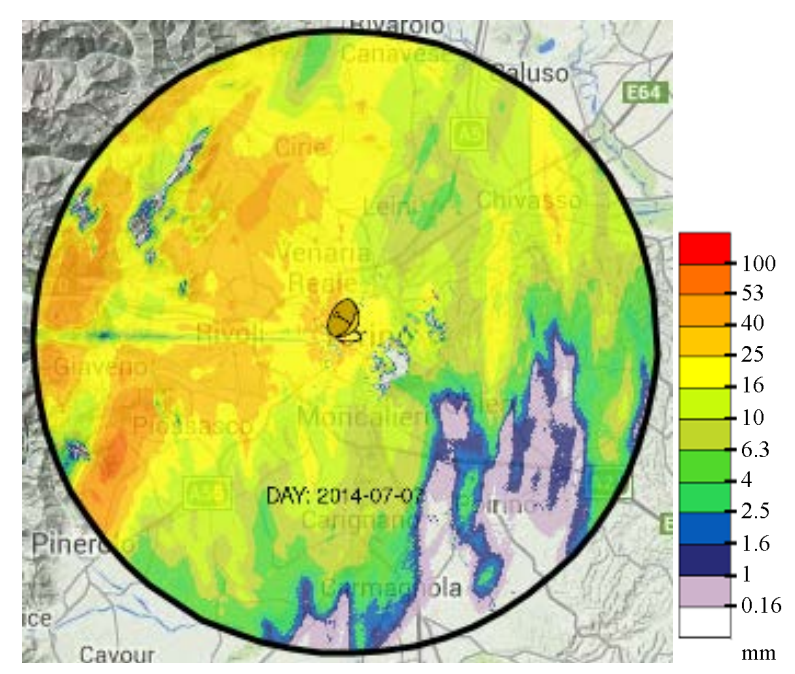

Figure 6. Daily cumulated rain measured by the X-band mini weather radar installed on the roof of Politecnico di Torino, related to $7^{\text {th }}$ July 2014.

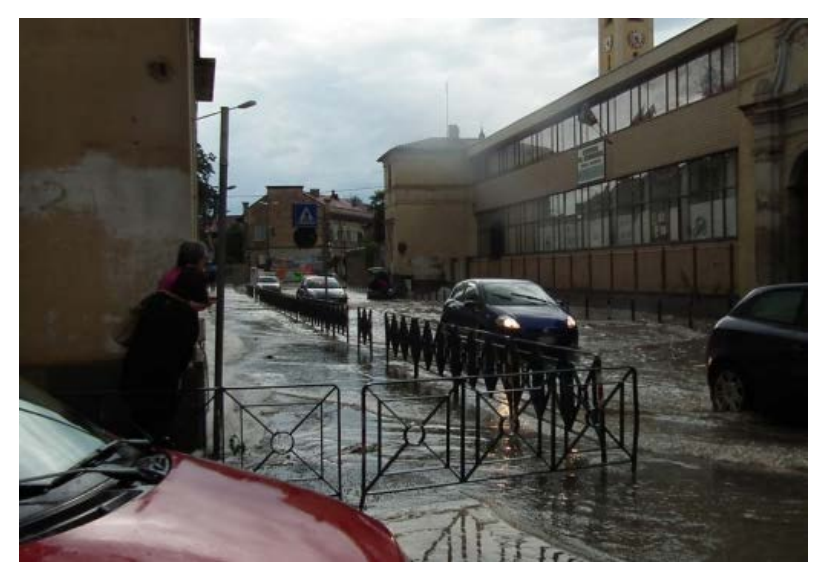

Figure 7. Flood on the village of Rivarolo Canavese (province of Turin, Italy). Courtesy from "La Sentinella del Canavese” web journal (lasentinella.geolocal.it). 


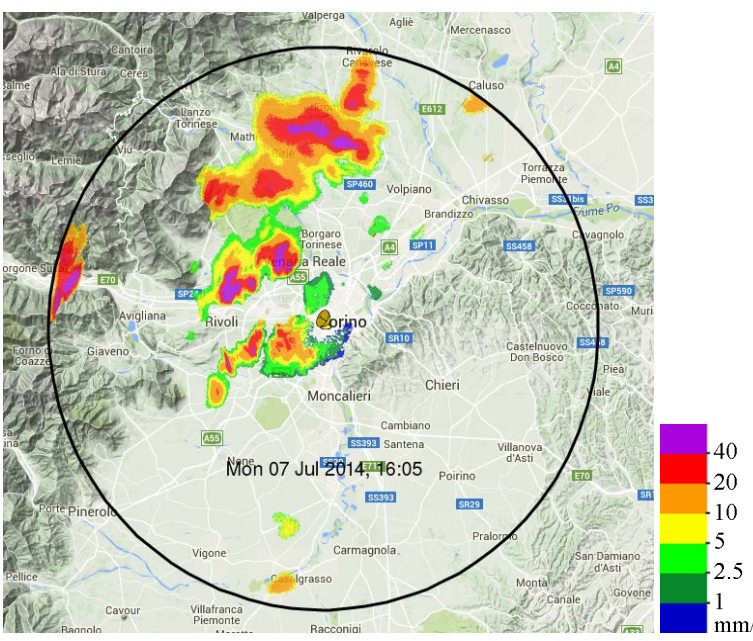

$7^{\text {th }}$ July h. 16.05 CEST

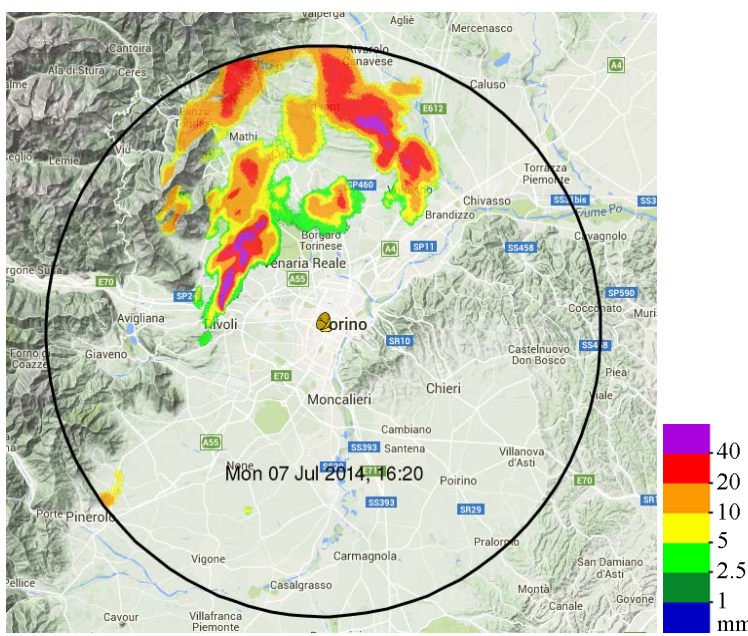

$7^{\text {th }}$ July h. 16.20 CEST

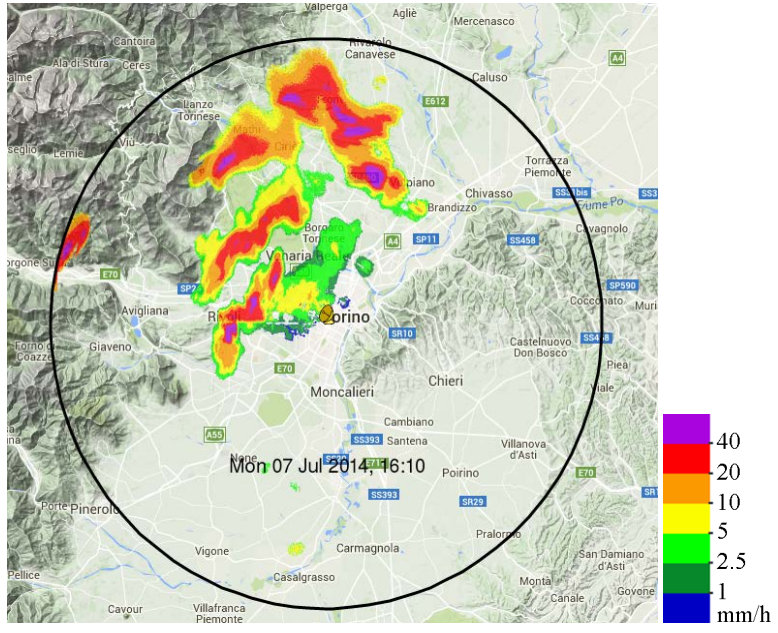

$7^{\text {th }}$ July h. 16.10 CEST

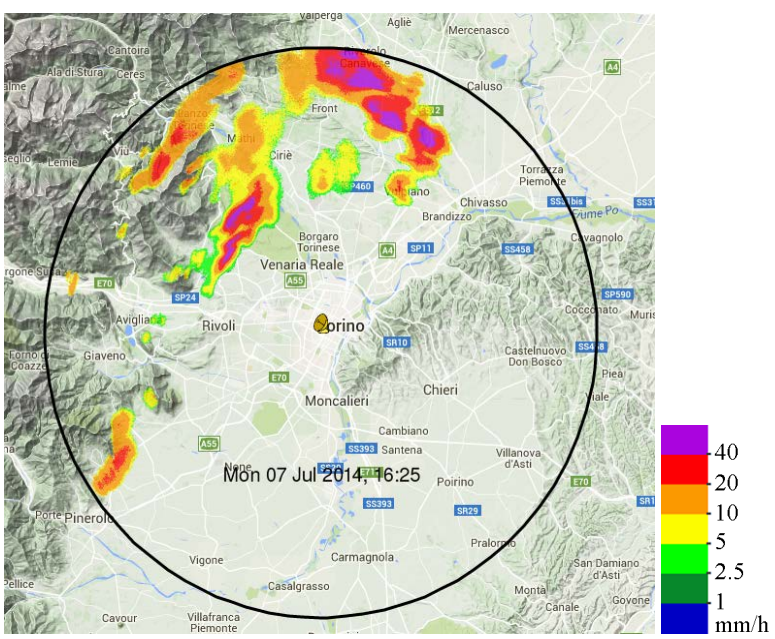

$7^{\text {th }}$ July h. 16.25 CEST

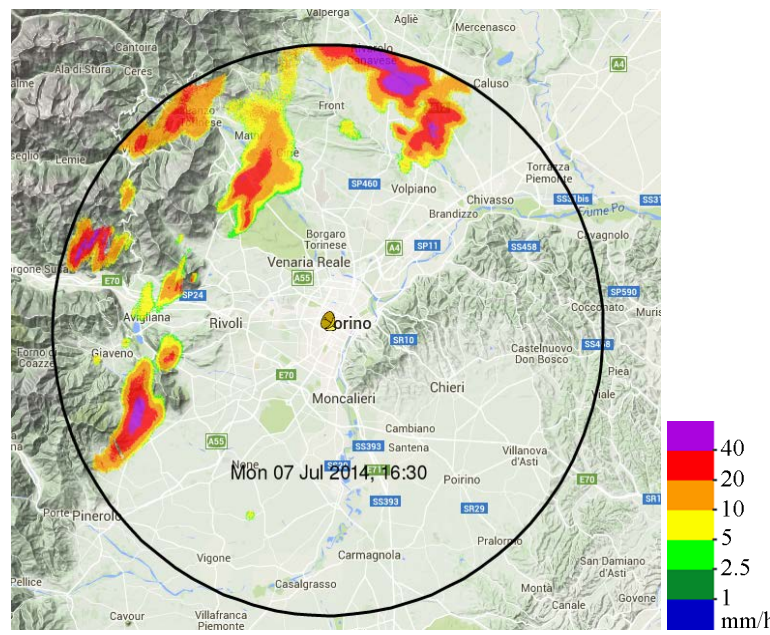

$7^{\text {th }}$ July h. 16.30 CEST

Figure 8. Significant maps showing the evolution of the thunderstorm in the Northern part of the area monitored by the $\mathrm{X}$-band mini weather radar. 
more than an hour, since lots of underpasses were flooded by more than $40 \mathrm{~mm}$ of water (Figure 9). The radar measured a rainfall rate of more than $40 \mathrm{~mm} / \mathrm{h}$ for more than 60 consecutive minutes. The significant real time radar maps are reported in Figure 10. They highlight the persistence of the intense meteorological event over the same area for more than a 1.5 hour.

3) Between 19.00 CEST and 19.30 CEST the intense rainfall event described above moved over the city of Turin. It was forerun by a so called "shelf cloud" clearly visible on the sky above the city which usually indicates an imminent thunderstorm (Figure 11). Also in this case, the radar reflectivity measurements allow to estimate a rainfall rate up to $40 \mathrm{~mm} / \mathrm{h}$. Some significant real time radar maps are reported in the following Figure 12.

\section{2. $20^{\text {th }}$ July 2014}

Although with less frequency with respect to $7^{\text {th }}$ July 2014, the day of $20^{\text {th }}$ July 2014 was a second day of extreme rainfall events occurred near Turin, as shown in the daily cumulated rain map in Figure 13.

The radar starts to monitor the first heavy rainfall events on the South-Western part of the monitored area during the late afternoon. Starting from 19.00 CEST the thunderous cells move from South to North following the Alps on the Western part of radar maps. In this case it is evident how the orography can influence the formation and the movement of rain fields, which can be controlled by the relief themselves and by the generated winds. It was possible to observe in real time this phenomenon thanks to the high temporal and spatial resolution of radar maps.

Two very intense rainfall events occurred during this day, both of them between 21.15 CEST and 22.00 CEST and both of them with a measured rain rate of more than $50 \mathrm{~mm} / \mathrm{h}$. The first one was detected and monitored on the North-Western part of the radar maps (highlighted in blue in Figure 14) and the second on the South-Western (highlighted in green in Figure 14). After these two major events another smaller intense thunderstorm occurred over the city of Turin between 22.15 CEST to 23.00 CEST.

\section{3. $23^{\text {rd July } 2014}$}

The last examined day is the $23^{\text {rd }}$ July 2014. During this day some extreme events occurred but the rain intensity was lower than during the previous ones, as it is also shown in the daily cumulated rain map reported in Figure 15.

However it is important to highlight the thunderstorm occurred over the city of Turin between the 15.00 CEST and 15.50 CEST. It was a localized intense event which lasted less than 1 hour, but its intensity provokes the falling of branches of trees which damages to the tram power lines causing disruption in the local public transport (Figure 16).

Evidence of this event is reported on the maps acquired in real time by the $\mathrm{X}$-band mini weather radar (Figure 17). It is a noteworthy fact that the radar allows to monitor also events occurring near its installations, if the measurements are, of course, not affected by ground clutter echoes which should be properly filtered out.

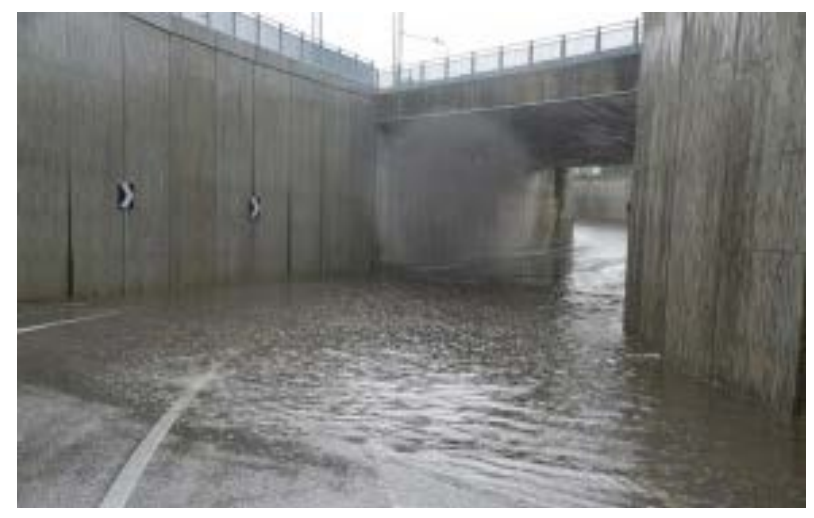

Figure 9. Underpass flooded in Pinerolo (Province of Turin, Italy). Courtesy from “L’Eco del Chisone” web journal (www.ecodelchisone.it). 


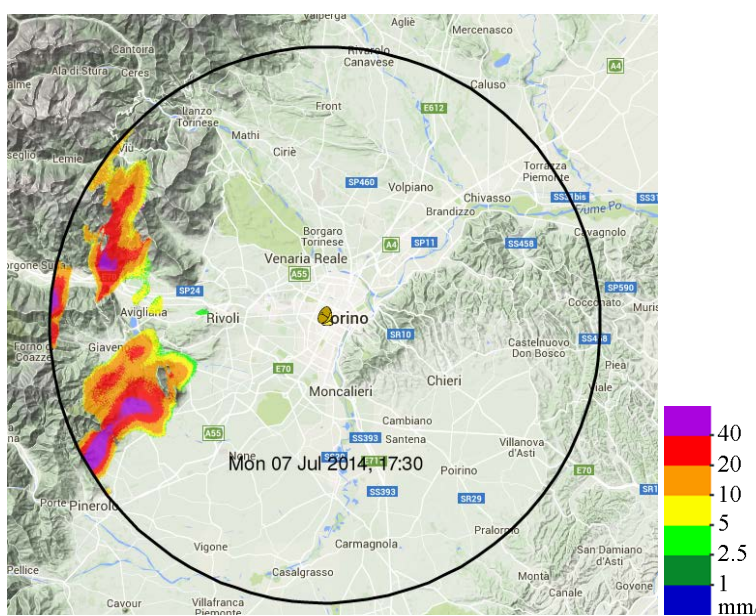

$7^{\text {th }}$ July h. 17.30 CEST

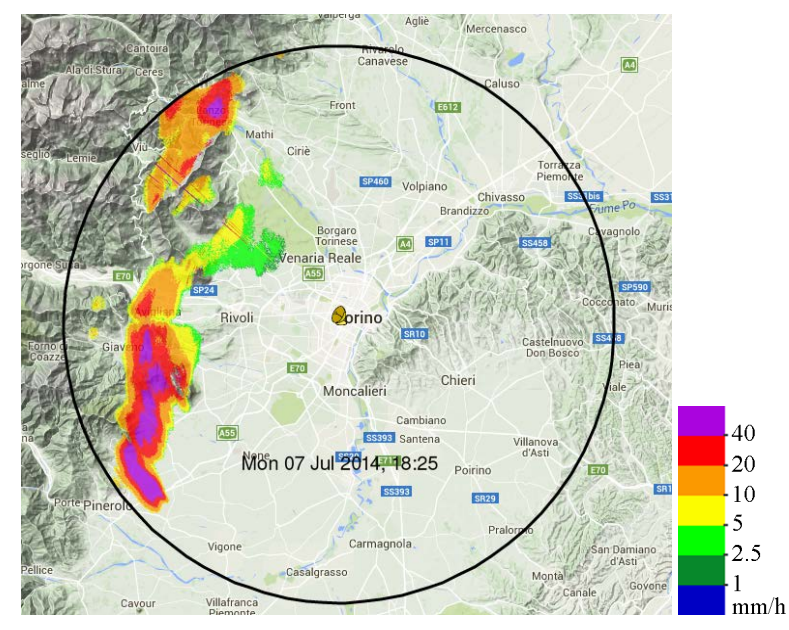

$7^{\text {th }}$ July h. 18.25 CEST

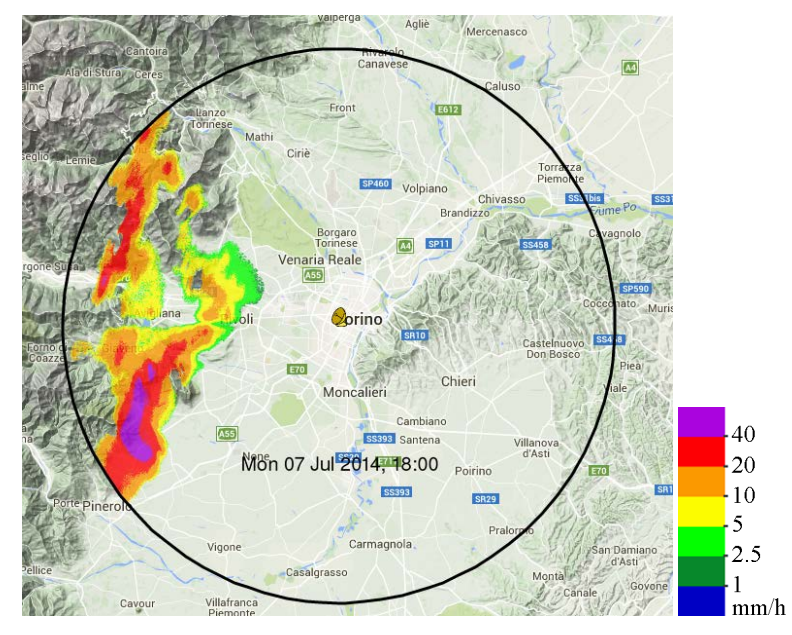

$7^{\text {th }}$ July h. 18.00 CEST

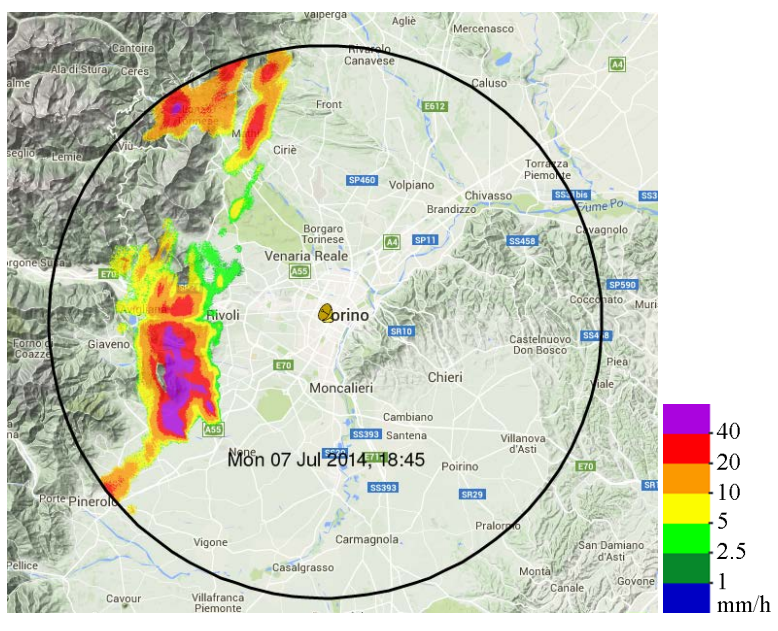

$7^{\text {th }}$ July h. 18.45 CEST

Figure 10. Significant maps showing the persistence of the extreme rainfall events in the South-Western part of the radar maps.

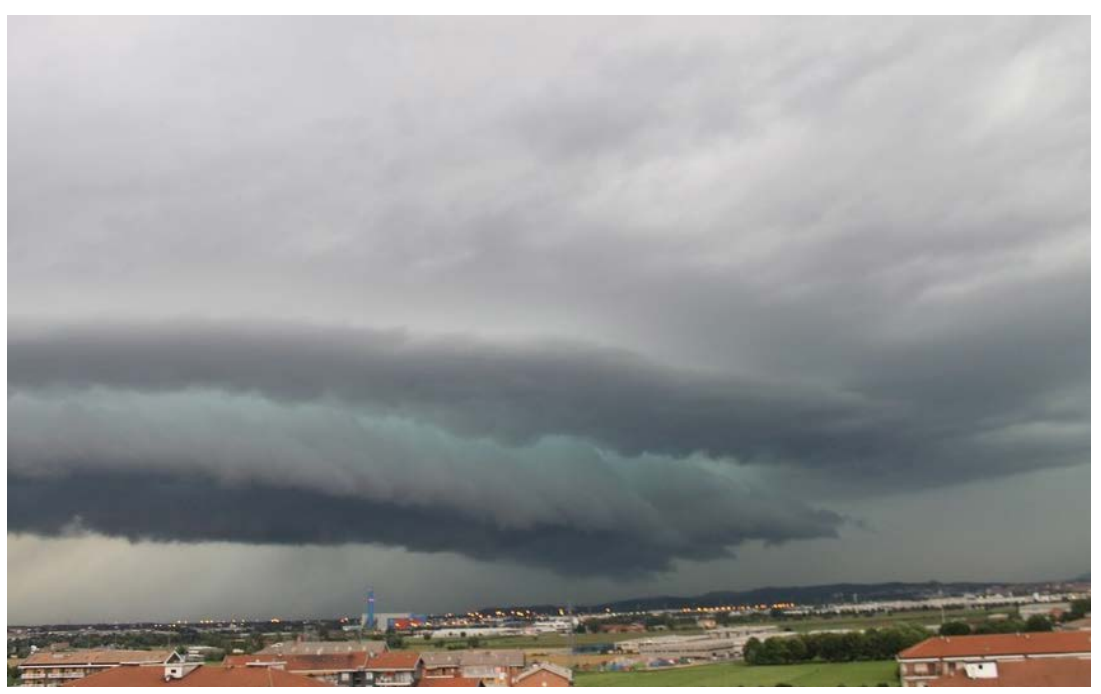

Figure 11. "Shelf Cloud” over Turin. Courtesy from website www.youreporter.it 

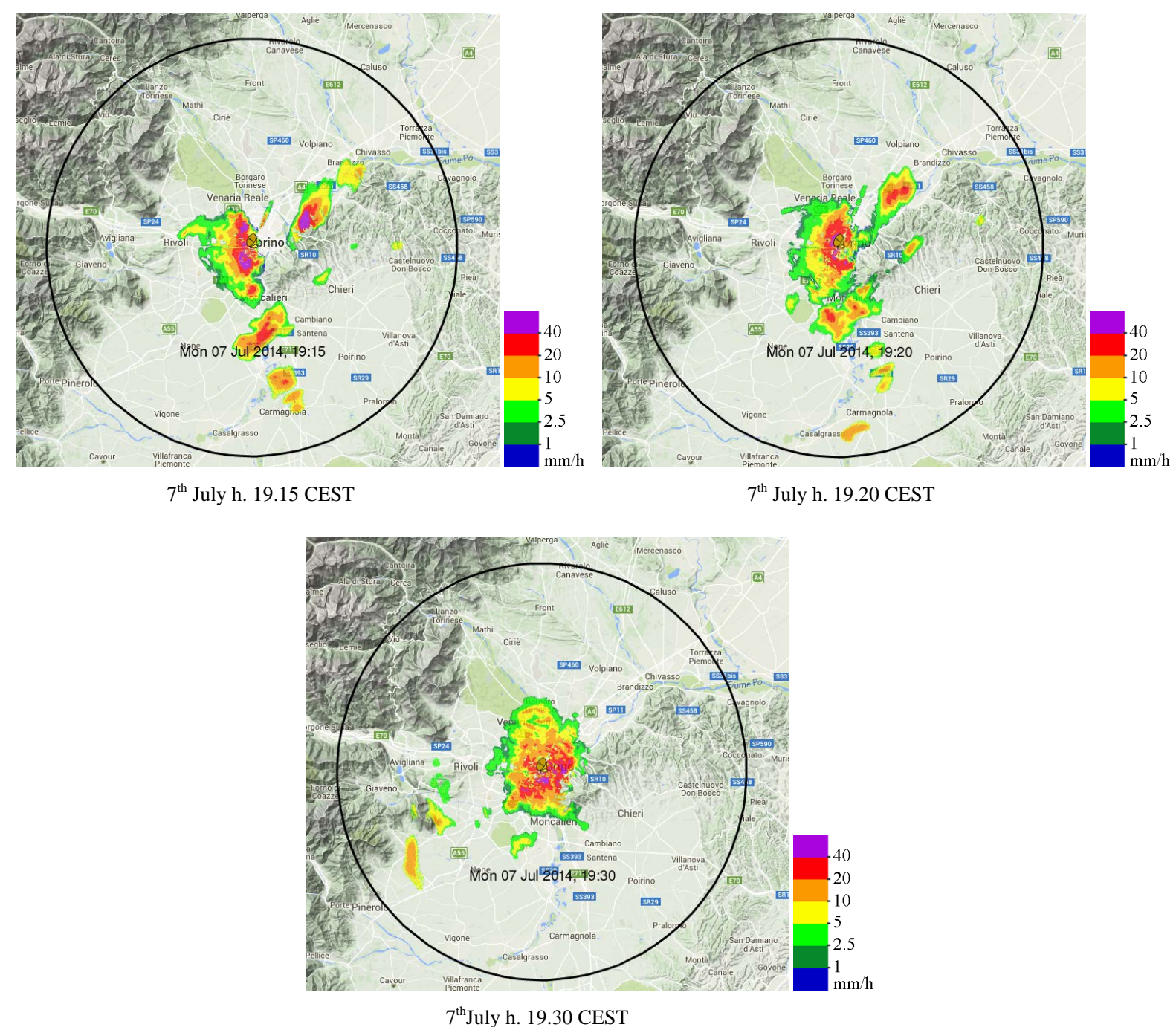

Figure 12. Significant maps showing the extreme rainfall event over the city of Turin, placed in the center of the map.

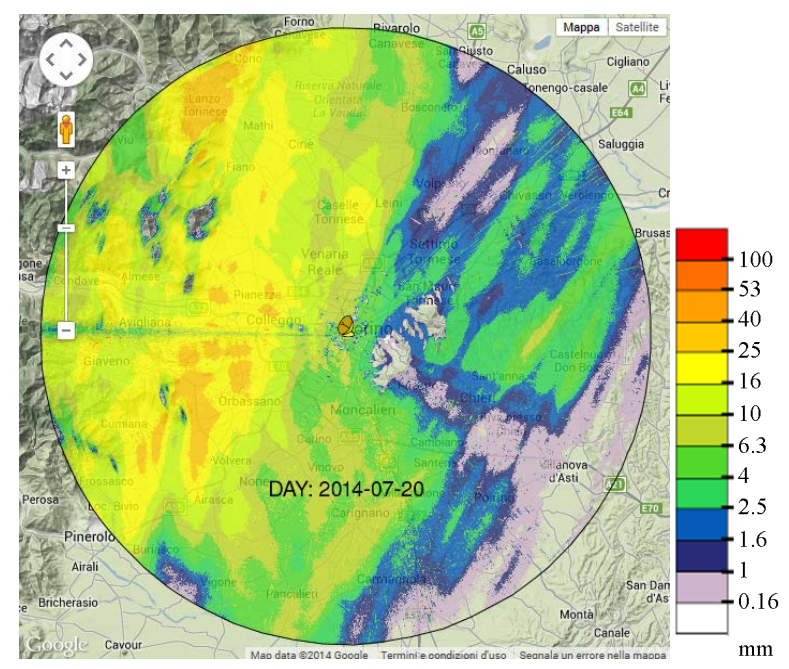

Figure 13. Daily cumulated rain measured by the X-band mini weather radar related to $20^{\text {th }}$ July 2014. 

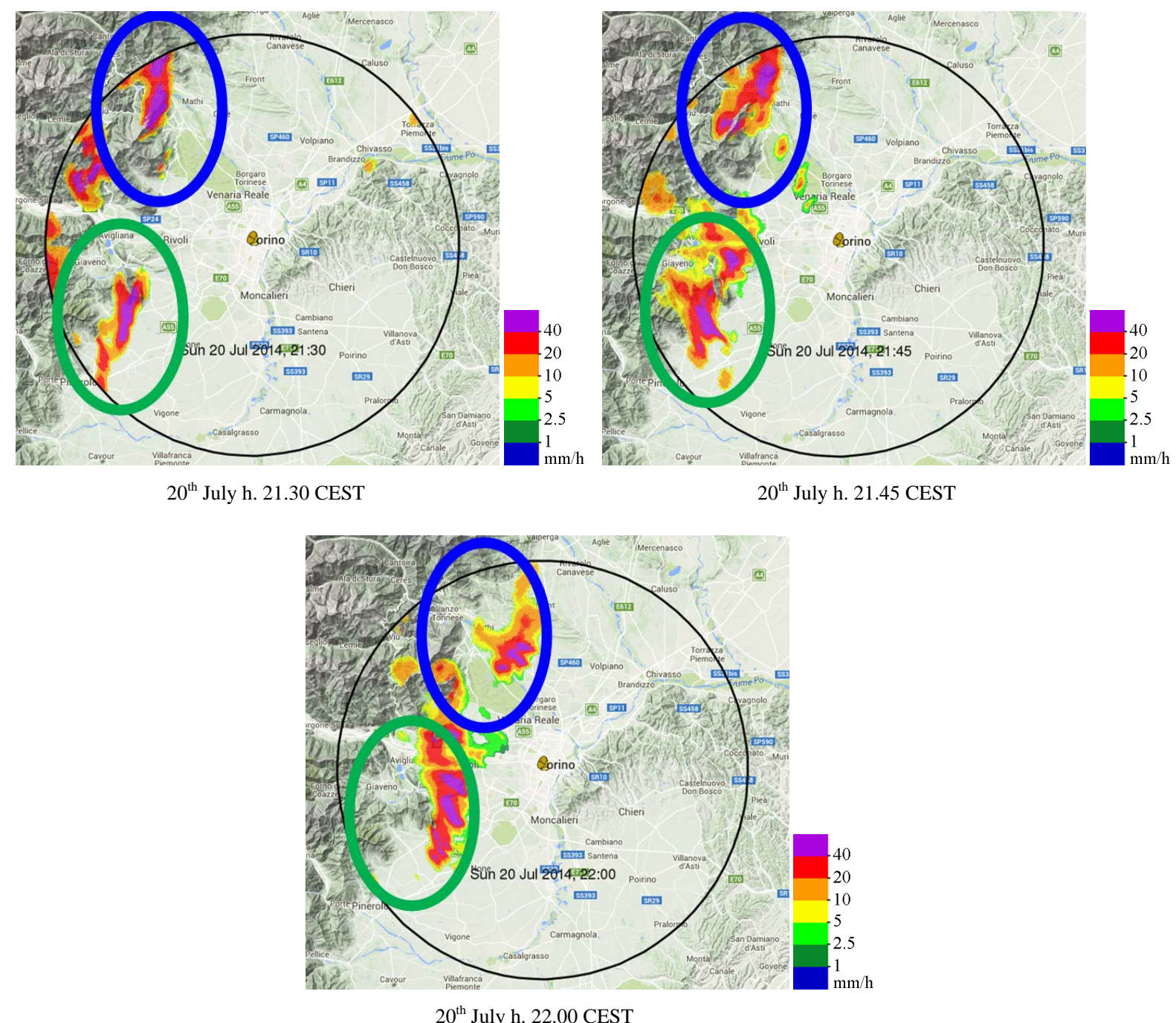

Figure 14. Examples of radar maps showing the two extreme rainfall events occurred on the evening of $20^{\text {th }}$ July 2014.

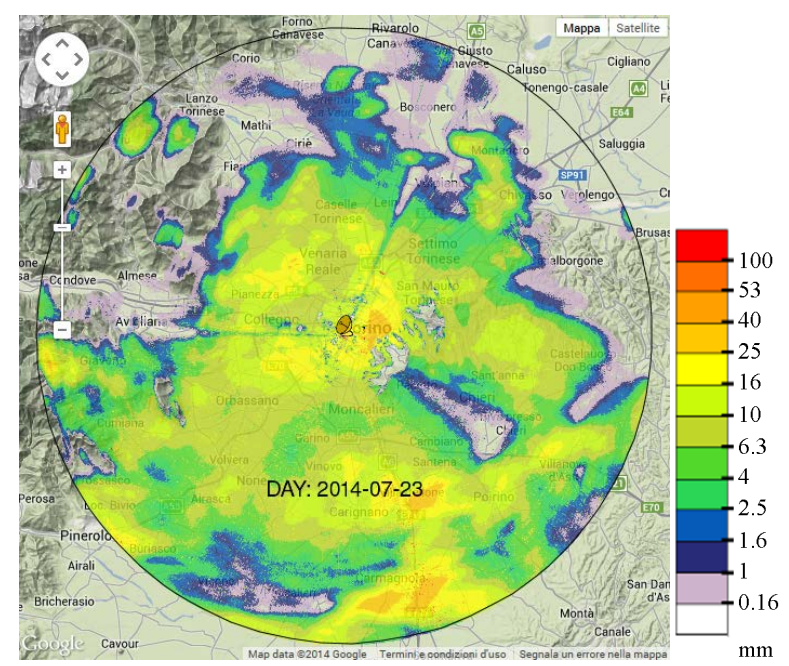

Figure 15. Daily cumulated rain measured by the X-band mini weather radar related to $23^{\text {th }}$ July 2014. 


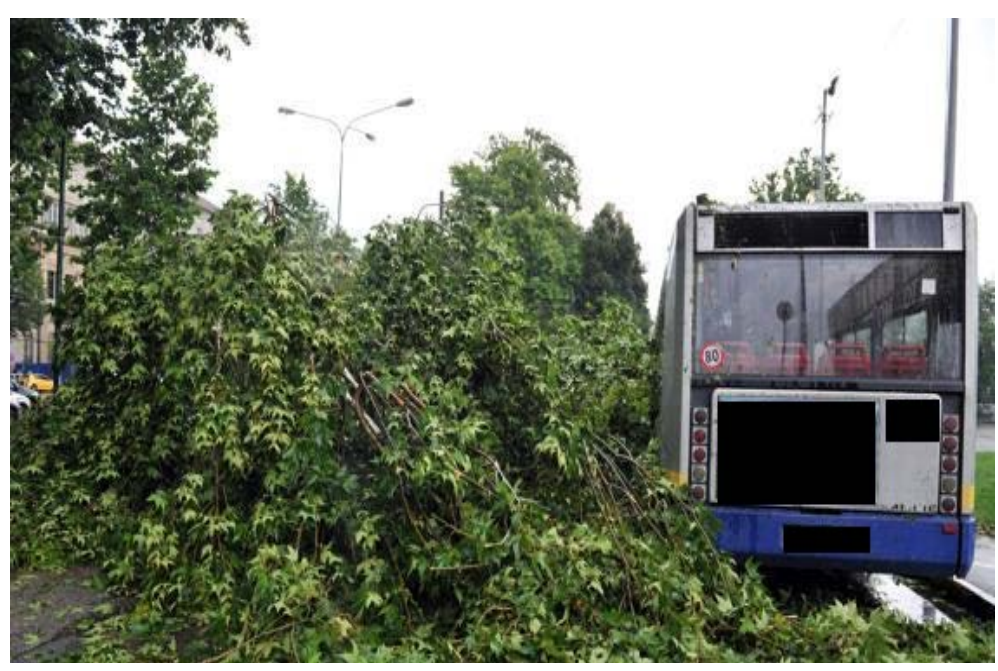

Figure 16. Branches of trees fallen which caused disruptions in local public transport.

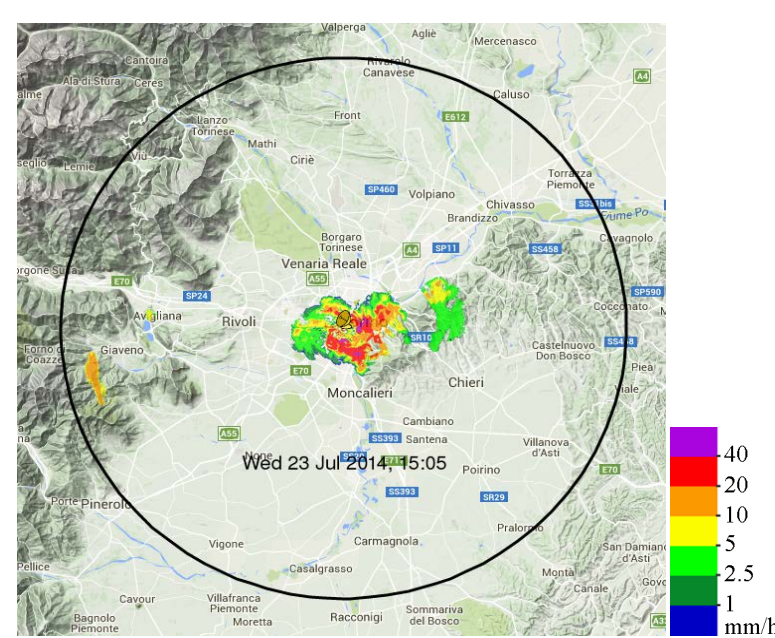

$23^{\text {th }}$ July h. 15.05 CEST

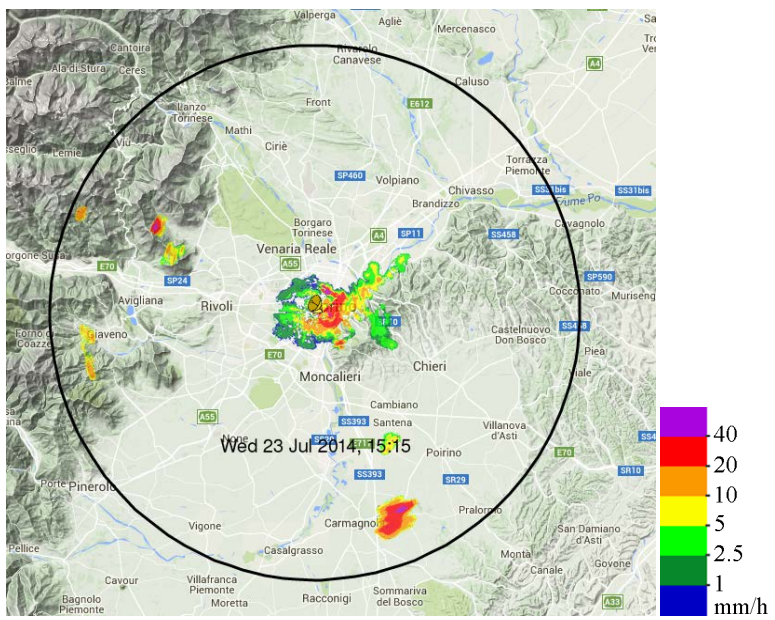

$23^{\text {th }}$ July h. 15.15 CEST

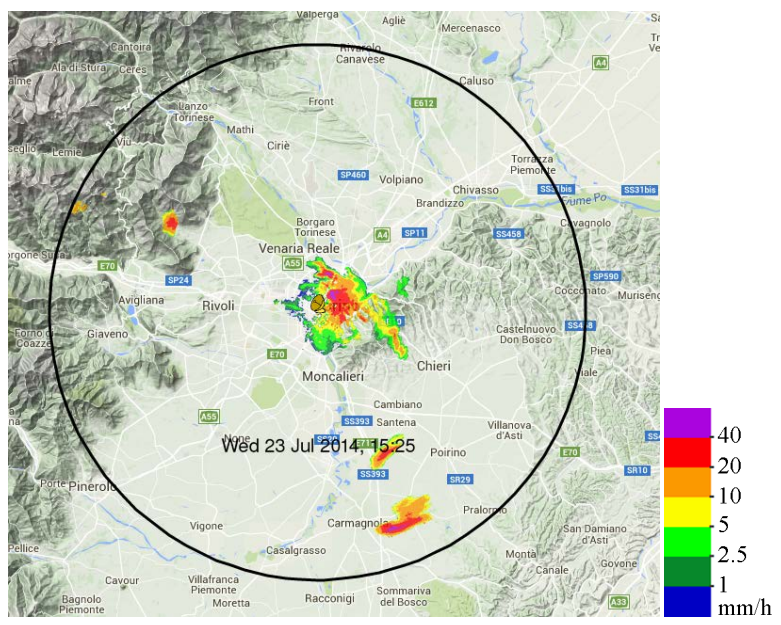

$23^{\text {th }}$ July h. 22.00 CEST

Figure 17. Examples of radar maps showing the two extreme rainfall events occurred over Turin on $23^{\text {th }}$ July 2014. 


\section{Conclusions and Outlooks}

This work shows that a simple X-band mini weather radar is a very useful instrument for real time monitoring extreme precipitation events and thunderstorms. The radar is non-coherent, non-Doppler with single vertical polarization so it is not possible to study in details the nature of the precipitation (e.g. hail, ice pallets, raindrops size). But if the radar is well calibrated, it can measure the reflectivity and estimate the rainfall rate in a precise manner all over the portion of the territory monitored, thus avoiding the installation of a huge number of rain gauges. The system high resolution, both in time and in space, allows to identify and track the rain cells and, with proper algorithms (e.g. in [14]) to forecast the evolution of the precipitation patterns in quasi-real time.

The simplicity of this system allows even non-qualified operators and specialized technician to use it. For instance, Civil Protection operators which are often volunteers may easily use it to monitor the rain during extreme events or during persistence events where flood are possible.

The radar maps archived in a well-designed database will allow also future statistical analysis and studies of extreme events over a small circular area with a radius of $30 \mathrm{~km}$. In fact it is possible to evaluate the Generalized Extreme Value (GEV) distributions using such data. Some studies of GEV were already made over a flatland area in Netherlands using X-band weather radar [15] [16]. Outlooks for the future will be to perform GEV studies over a complex orography environment using the instruments described in this work, in order to make the radar useful not only for real time monitoring of rain fields and QPE, but also for some climatological studies. First results were already presented in [17] and gave very encouraging hopes for the future even if compared with classical GEV parameters estimation using large series rain gauges data [18].

\section{Acknowledgements}

The present study was part of the work made within the framework of a research project between the local unit of CINFAI (Consorzio Interuniversitario Nazionale per la Fisicadelle Atmosfere) at the Department of Electronic and Telecommunication at Politecnico di Torino, ALMA Ingegneria s.r.l and T4B s.r.l within the project “IDRORADAR" financed by the Regione Piemonte, Italy, where the use of X-band weather radar to monitor rain fields, with particular focus on complex orography environment, was investigated.

A special thanks is due to ARPA (Azienda Regionale Protezione Ambientale) Piemonte, Italy, for to the free availability of meteorological and climatological data from its Regional Database of Weather Data.

Photos are taken from web journal archives of La Sentinella del Canavese (lasentinella.geolocal.com), L'Eco del Chisone (www.ecodelchisone.it), La Stampa (www.lastampa.it).

\section{References}

[1] Van de Beek, C.Z., Leijnse, H., Stricker, J.N.M., Uijlenhoet, R. and Russchenberg, H.W.J. (2009) Performance of High Resolution X-Band Radar for Rainfall Measurement in The Netherlands. Hydrology and Earth System Sciences Discussion, 6, 6035-2085. http://dx.doi.org/10.5194/hessd-6-6035-2009

[2] Gabella, M. and Notarpietro, R. (2004) Improving Operational Measurement of Precipitation Using Radar in Mountainous Terrain-Part I: Methods. IEEE Geosciences and Remote Sensing Letters, 1, 78-83. http://dx.doi.org/10.1109/LGRS.2003.822311

[3] Gabella, M. and Notarpietro, R. (2004) Improving Operational Measurement of Precipitation Using Radar in Mountainous Terrain—Part II: Verification and Application. IEEE Geosciences and Remote Sensing Letters, 1, 84-89. http://dx.doi.org/10.1109/LGRS.2003.823294

[4] Bertoldo, S. (2014) X-Band Mini Weather Radar Network and Other Wireless Sensor Network for Environmental Monitoring. PhD Thesis, Politecnico di Torino, Turin.

[5] Gabella, M., Notarpietro, R., Bertoldo, S., Prato, A., Lucianaz, C., Rorato, O., Allegretti, M. and Perona, G. (2012) A Network of Portable, Low-Cost, X-Band Radar. In: Bech, J., Ed., Doppler Radar Observations—Weather Radar, Wind Profiler, Ionospheric Radar, and Other Advanced Applications, InTech, Rijeca, 175-202.

[6] Notarpietro, R., Branca, M., Morin, E., Lokshin, A., Gabella, M., de Vita, P., Basso, B., Bonfil, D., Bertoldo, S., Shah, S., Lucianaz, C., Rorato, O. and Allegretti, M. (2013) Towards Sustainable Agricultural Management Using HighResolution X-Band Radar Precipitation Estimates. IEEE International Conference on Electromagnetics in Advanced Applications (ICEAA), Torino, 9-13 September 2013, 915-918. http://dx.doi.org/10.1109/ICEAA.2013.6632373

[7] Allegretti, M., Bertoldo, S., Prato, A., Lucianaz, C., Rorato, O., Notarpietro, R. and Gabella, M. (2012) X-Band Mini Radar for Observing and Monitoring Rainfall Events. Atmospheric and Climate Sciences, 2, 290-297. 
http://dx.doi.org/ 10.4236/acs.2012.238

[8] Bertoldo, S., Bracco, L., Notarpietro, R., Lucianaz, C., Rorato, O. and Allegretti, M. (2012) A Standalone Application to Monitor the Radar Stability of a Low Cost Maintenance Free X-Band Mini Weather Radar, Using Ground Clutter Echoes. International Conference on Electromagnetics in Advanced Applications (ICEAA), Cape Town, 2-7 September 2012, 1040-1043. http://dx.doi.org/10.1109/ICEAA.2012.6328781

[9] Bertoldo, S., Bracco, L., Notarpietro, R., Branca, M., Gabella, M., Lucianaz, C., Rorato, O., Allegretti, M. and Perona, G. (2012) Clutter Analysis to Monitor the Stability of a Portable X-Band Mini Weather Radar. Urban Rain 2012-9th International Workshop on Precipitation in Urban Areas, St. Moritz, Switzerland, 6-9 December 2012, 171-176.

[10] Bertoldo, S., Notarpietro, R., Branca, M., Dassano, G., Lucianaz, C., Rorato, O. and Allegretti, M. (2013) Characterization of the Receiver Filter of a X-Band Weather Radar to Improve the Performance of an Application to Control the Radar Stability. International Conference on Electromagnetics in Advanced Applications (ICEAA), Torino, 9-13 September 2013, 1040-1043. http://dx.doi.org/10.1109/ICEAA.2013.6632376

[11] Joss, J. and Waldvogel, A. (1990) Precipitation Measurements and Hydrology. In: Atlas, D., Ed., Radar in Meteorology, America Meteorological Society, Boston, 577-606.

[12] Il clima in Piemonte-Luglio (2014) Arpa Piemonte, Dipartimento dei Sistemi Previsionali, August 2014.

[13] Eventi temporaleschi nel mese di Luglio (2014) Arpa Piemonte, Dipartimento dei Sistemi Previsionali, August 2014.

[14] Shah, S., Notarpietro, R., Bertoldo, S., Branca, M., Lucianaz, C., Rorato, O. and Allegretti, M. (2013) Automatic Storm(s) Identification in High Resolution, Short Range, X-Band Radar Images. International Conference on Electromagnetics in Advanced Applications (ICEAA), Torino, 9-13 September 2013, 945-948.

http://dx.doi.org/10.1109/ICEAA.2013.6632379

[15] Overeem, A., Buishand, A. and Holleman, I. (2009) Extreme Rainfall Analysis and Estimation of Depth-DurationFrequency Curves Using Weather Radar. Water Resources Research, 45, Article ID: W10424. http://dx.doi.org10.1029/2009WR007869

[16] Overeem, A., Buishand, A., Holleman, I. and UiJlenhoet, R. (2010) Extreme Value Modeling of Areal Rainfall from Weather Radar. Water Resources Research, 46, Article ID: W09514. http://dx.doi.org/10.1029/2009WR008517

[17] Bertoldo, S., Allegretti, M., Greco, G. and Lucianaz, C. (2015) Extreme Rain Events Analysis Using X-Band Weather Radar. International Conference on Electromagnetics in Advanced Applications (ICEAA), Torino, 7-11 September 2015, 157-160. http://dx.doi.org/ 10.1109/ICEAA.2015.7297094

[18] Bertoldo, S., Lucianaz, C. and Allegretti, M. (2015) Extreme Rainfall Event Analysis Using Rain Gauges in a Variety of Geographical Situations. Atmospheric and Climate Sciences, 5, 82-90. http://dx.doi.org/ 10.4236/acs.2015.52006. 